\title{
Month of birth and risk of developing insulin dependent diabetes in south east Sweden
}

\author{
Ulf Samuelsson, Calle Johansson, Johnny Ludvigsson
}

\begin{abstract}
Environmental factors very early in life may be important for later development of insulin dependent diabetes. Because several of these factors, such as infections, vary with season, we predicted a difference in birth pattern compared with the general population among children who develop diabetes. In a population based study we analysed all 1248 children from seven paediatric departments in the south east part of Sweden to evaluate whether there is such a relation. There was a significant difference in birth pattern in patients with diabetes compared with the general population. Children who developed diabetes at the age of 10-15 years accounted for most of this difference. Boys had a more pronounced difference in birth pattern than girls. Children diagnosed with diabetes during years of high incidence, as well as children with an infection before diagnosis of diabetes, showed a significantly different birth pattern compared with the background population. These results indicate that there is a difference in birth pattern in children who develop diabetes compared with the background population. This supports the theory that environmental factors early in life play a role in the development of diabetes many years later. (Arch Dis Child 1999;81:143-146)
\end{abstract}

Keywords: insulin dependent diabetes; birth pattern; infection; incidence

The cause of insulin dependent diabetes is unknown but genetic and environmental factors and autoimmune mechanisms are involved in the pathogenesis. ${ }^{12}$

Several studies have reported that physical, psychological, or chemical stresses can produce imbalance in the proportions of $\mathrm{T}$ cell subsets, immunoglobulin levels, and lymphocyte reactivity. ${ }^{3-5}$ There is also a seasonal variation in several immune variables, which could imply that some immunological abnormalities could be explained by seasonality. In turn, this might contribute to the onset or progression of certain diseases such as diabetes and allergy. ${ }^{6}$ In allergy, early infancy seems to be a period of particular susceptibility to sensitisation, ${ }^{78}$ and several studies have found a relation between month of birth, sensitisation, and manifestation of atopy. ${ }^{9} 10$

There is a clear seasonal variation in the diagnosis of diabetes, ${ }^{11}{ }^{12}$ and children diagnosed during high incidence peaks more often have a preceding, perhaps precipitating, infection. ${ }^{13}$ These children have higher IgM and IgG levels and they lose their C-peptide more rapidly than patients diagnosed during periods of lower incidence. ${ }^{13}{ }^{14}$ However, seasonal factors could influence not only precipitating mechanisms just before diagnosis, but also initiating or promoting mechanisms very early in the disease process.

In 1981 Helgasson and Jonasson ${ }^{15}$ showed that the incidence of diabetes in Icelandic boys diagnosed at $0-14$ years of age and born in October was higher than expected. They suggested that the presence of high concentrations of $N$-nitroso compounds, common food additives, and smoked/cured mutton contributed to the development of diabetes, not in the consumer but in the progeny. This is supported by animal studies. Male offspring of mice fed with cured mutton had increased glucose levels and evidence of $\beta$ cell destruction. ${ }^{16}$ Seasonal variation in nutrition or infections might influence pregnant mothers and their fetuses, or the baby during its early life. Two studies have confirmed the relation between month of birth and the risk of developing diabetes, ${ }^{17}{ }^{18}$ although another study failed to confirm this relation. ${ }^{19}$ A recent Swedish study showed fewer children than expected who had developed diabetes were born in October, but this was not significant. ${ }^{20}$

We performed a population based study to find out: (1) whether there is a relation between month of birth and the risk of developing insulin dependent diabetes; and (2) whether such an association is related to certain background events.

\section{Methods}

We recruited 1248 children (702 boys, 546 girls) from seven paediatric departments in the south east part of Sweden. These children had developed diabetes at $<16$ years of age and had been diagnosed between 1977 and 1994 and born between 1962 and 1992. The catchment areas of these clinics form a contiguous geographical area of $42356 \mathrm{~km}^{2}$.

From their medical records we extracted information regarding date of birth, sex, and date of diagnosis (first insulin injection), together with information about infections within the three months before diagnosis and duration of symptoms before diagnosis, blood glucose values and ketonuria at diagnosis. The Swedish system of centralised care of children with diabetes means that all cases are registered. In addition, we found complete concordance with the reports to the Swedish Childhood Diabetes Registry. ${ }^{21}$ From the Swedish 
Table 1 Ratio between observed live births and expected live births (O/E) of children who later developed diabetes Data are given in relation to the total number of children, the different age groups, between boys and girls, and between children who were infected and not infected 0-3 months before diagnosis

\begin{tabular}{|c|c|c|c|c|c|c|c|c|c|c|c|c|c|c|c|c|c|c|c|c|c|c|}
\hline \multirow{2}{*}{$\begin{array}{l}\text { Birth } \\
\text { month }\end{array}$} & \multicolumn{2}{|c|}{ Live births } & \multicolumn{3}{|c|}{$O / E$ (all children) } & \multicolumn{2}{|c|}{ Live births } & \multicolumn{3}{|c|}{$O / E$ (0-4 years) } & \multicolumn{2}{|c|}{ Live births } & \multicolumn{3}{|c|}{$O / E$ (5-9 years) } & \multicolumn{2}{|c|}{ Live births } & \multicolumn{3}{|c|}{$O / E(10-15$ years $)$} & \multirow{2}{*}{$\begin{array}{l}O / E \\
\text { infected }\end{array}$} & \multirow{2}{*}{$\begin{array}{l}\text { Not } \\
\text { infected }\end{array}$} \\
\hline & Total & $D$ & Total & $M$ & $F$ & Total & $D$ & Total & $M$ & $F$ & Total & $D$ & Total & $M$ & $F$ & Total & $D$ & Total & $M$ & $F$ & & \\
\hline 1 & 40202 & 99 & 0.99 & 0.91 & 1.09 & 24592 & 16 & 1.00 & 0.67 & 1.42 & 28507 & 36 & & 1.05 & 1.21 & & 47 & 0.87 & 0.87 & & & 0.94 \\
\hline 2 & 40385 & 105 & 1.04 & 1.05 & 1.02 & 26086 & 23 & 1.35 & 1.10 & 1.71 & 28507 & 23 & 1.00 & 0.67 & 0.78 & 31764 & 59 & 1.11 & 1.23 & 0. & 1.2 & 0.90 \\
\hline 3 & 47494 & 117 & 0.98 & 1.07 & 0.86 & 30342 & 24 & 1.20 & 1.36 & 1.00 & 33560 & 33 & 0.85 & 0.95 & 0.71 & 36169 & 60 & 1.00 & 1.05 & 0.92 & 1.04 & 0.98 \\
\hline 4 & 48923 & 115 & 0.94 & 1.07 & 0.78 & 29785 & 20 & & 1.80 & 0.78 & 33230 & 46 & 1.20 & 1.28 & 1.11 & 38027 & 49 & $0.78+$ & 0.92 & $0.57 \dagger$ & 0.78 & 1.03 \\
\hline 5 & 46453 & 108 & 0.93 & 0.92 & 0.94 & 28601 & 17 & 0.89 & 1.09 & 0.63 & 31632 & 39 & 1.05 & 1.10 & 1.06 & 35819 & 52 & 0.87 & 0.79 & $0.96^{\circ}$ & 0.95 & 0.90 \\
\hline 6 & 42405 & 110 & 1.04 & 0.98 & 1.10 & 26396 & 24 & 1.33 & 1.20 & 1.50 & 28952 & 30 & 0.90 & 0.94 & 0.87 & 32440 & 56 & 1.04 & 0.97 & 1.12 & 1.19 & 1.00 \\
\hline 7 & 42161 & 118 & 1.12 & 1.17 & 1.06 & 26228 & 13 & 0.72 & 0.90 & 0.50 & 28748 & 35 & 1.06 & 1.16 & 0.93 & 32143 & 70 & $1.32 \Phi$ & $1.30 \ddagger$ & $1.35 \ddagger$ & 1.11 & 1.14 \\
\hline 8 & 40338 & 126 & 1.25 & $1.24 \dagger$ & $1.15 \ddagger$ & 25172 & 21 & 1.23 & 1.44 & 1.14 & 28763 & 42 & 1.27 & 1.16 & 1.40 & 30574 & 63 & 1.23 & $1.23^{+}$ & $1.18^{+}$ & $1.28 \ddagger$ & 1.30 \\
\hline 9 & 40843 & 108 & 1.06 & 1.02 & 1.11 & 25138 & 15 & 0.88 & 1.00 & 0.86 & 28993 & 42 & 1.23 & 1.27 & 1.27 & 31196 & 51 & 0.98 & 0.89 & 1.08 & $1.20^{\mathrm{T}}$ & 0.91 \\
\hline 10 & 38780 & 64 & $0.66^{\star}$ & $0.57^{\star}$ & $0.79 \ddagger$ & 23452 & 10 & $0.62 \ddagger$ & 0.44 & 0.86 & 27671 & 24 & $0.75+$ & 0.67 & 0.86 & 30007 & 30 & $0.60^{\star}$ & 0.53 & 0.6 & $0.45^{\star}$ & 0.74 \\
\hline 11 & 35765 & 86 & 0.97 & 1.00 & 0.92 & 21608 & 10 & & 0.75 & 0.6 & 25326 & 30 & 1.03 & 1.00 & 1.08 & 27713 & 46 & 1.00 & 1.08 & 0.90 & & 1.14 \\
\hline 12 & 35544 & 92 & 1.04 & 0.96 & 1.16 & 21302 & 13 & 0.93 & 0.88 & 1.00 & 23916 & 22 & 0.78 & 0.80 & 1.20 & 27345 & 57 & $1.27 \ddagger$ & 1.11 & 1.40 & 0.87 & 0.98 \\
\hline
\end{tabular}

Table also includes the total number of live births for each month and the number of births of children who later developed diabetes (D).

${ }^{\star} \mathrm{p}<0.01 ; \mathrm{tp}<0.05 ; \neq \mathrm{p}=0.1 ; \uparrow \mathrm{p}<0.02$.

Population Registry we obtained the sex, and year and month of birth for all children born in the geographical area during the timespan studied.

The study was approved by the ethics committee of the faculty of health sciences, Linköping University.

STATISTICAL ANALYSIS

Because this is an explorative study we tested our hypothesis regarding month of birth and diabetes by $\chi^{2}$ using the formula:

(observed $(\mathrm{O})$ - expected (E) $)^{2}$ /expected

Eleven degrees of freedom (df) were used when describing variation over the year and one degree of freedom when analysing a single month. When using the formula for a single month we also add in $(\mathrm{O}-\mathrm{E})^{2} / \mathrm{E}$ for the other 11 months taken together.

Expected values were calculated by the formula:

all live births for month $\times$ all diabetic cases (1248)/all live births in the area (499 293)

Thus, the 499293 children born during the same time and in the same geographical area were the reference standard.

Each subgroup was calculated by the same formula - for example, boys $702 / 257758 \times$ all liveborn boys born each month; and children $0-4$ years of age at diagnosis, 206/308 $702 \times$ all children 0-4 years of age born each month.

Some analyses were performed with $\chi^{2}$ test for $2 \times 12$ or $3 \times 12$ tables (crosstabs) and one way analysis of variance (ANOVA), using the

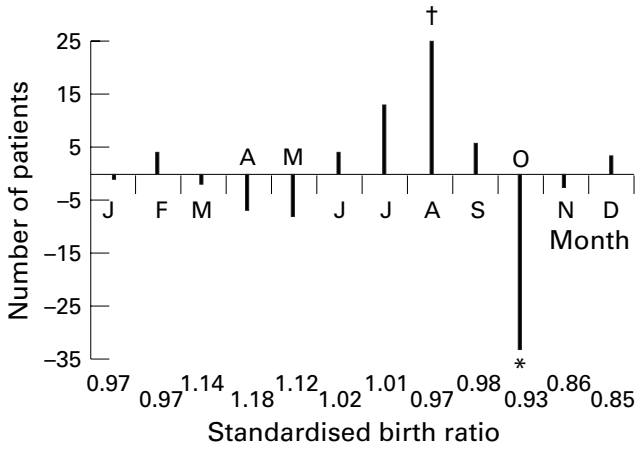

Figure 1 Seasonal variation in month of birth in the total cohort. The zero line indicates expected patients and the bars indicate observed patients. For example, in fuly there were 13 patients more than expected, whereas there were 33 less than expected in October. SBR, standardised birth ratio; ${ }^{\star} p<0.01 ;+p<0.02$. procedures of the statistical package for the Social Sciences for Windows (SPSS-WIN).

\section{Results}

Two hundred and six (16.5\%) of the children were $0-4$ years of age at the diagnosis of diabetes, $402(32.2 \%)$ were $5-9$ years, and 640 $(51.3 \%)$ were between 10 and 15 years of age. There was a small but significant difference in the monthly pattern of births in children with diabetes compared with the general population ( $\left.d f=1, \chi^{2}=20.87, p<0.04\right)$, mostly because fewer diabetic children than expected were born in October $\left(\chi^{2}=12.24, \mathrm{p}<0.01\right.$, $\mathrm{O} / \mathrm{E}=0.66$ ), especially boys (boys: $\mathrm{p}<0.01$, $\mathrm{O} / \mathrm{E}=0.57 ;$ girls: $\mathrm{p}=0.1, \mathrm{O} / \mathrm{E}=0.79)$ (table 1). Furthermore, more children with diabetes were born in August than expected $\left(\chi^{2}=6.68\right.$, $\mathrm{p}<0.02, \mathrm{O} / \mathrm{E}=1.25$ ) (fig 1 ). Boys had a more pronounced difference in the monthly pattern of births than did girls.

When analysing the three age groups we found a significant difference in birth seasonality $\left(\mathrm{p}<0.04 ; \chi^{2}\right)$ because children who developed diabetes at the age of 10-15 years accounted for most of the difference in variation over the year $\left(\mathrm{df}=11, \chi^{2}=24.27\right.$, $\mathrm{p}<0.02$ ) (fig 2). More children were born in July than expected $\left(\mathrm{df}=1, \chi^{2}=5.94, \mathrm{p}<0.02\right.$, $\mathrm{O} / \mathrm{E}=1.32$ ). Children $0-4$ years of age at onset of diabetes had no significant birth seasonality whereas fewer children 5-9 years of age at diagnosis were born in October $(\mathrm{df}=1$, $\left.\chi^{2}=4.05, \mathrm{p}<0.05, \mathrm{O} / \mathrm{E}=0.75\right)$ (table 1).

The overall annual incidence of insulin dependent diabetes for the study period was

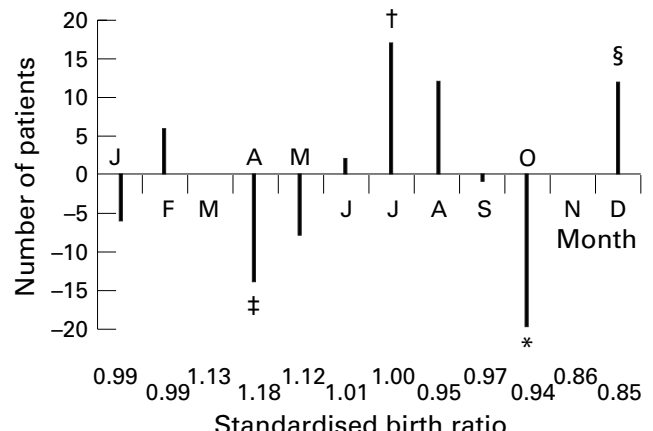

Figure 2 Seasonal variation in month of birth in children $10-15$ years of age at onset. SBR, standardised birth ratio; ${ }^{*} p<0.01 ; \neq p<0.02 ; \neq p<0.05 ; \int p=0.1$. 


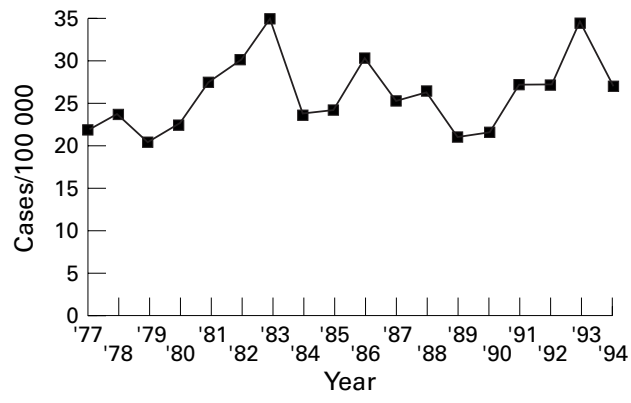

Figure 3 The annual incidence for each 100000 children $<16$ years of age in the seven paediatric departments during the study period. The highest peaks occurred in 1983 and 1993.

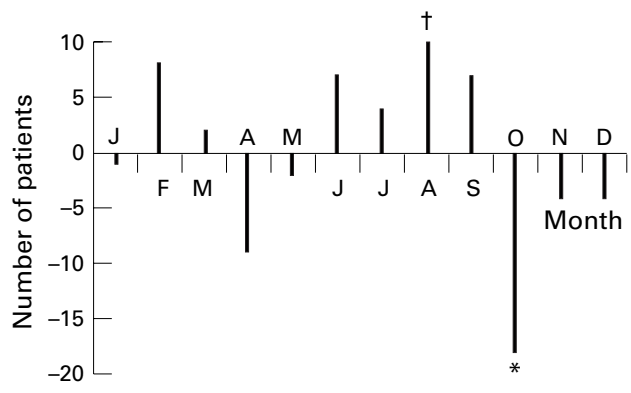

Figure 4 The seasonal variation in month of birth in children with an infection before diagnosis. ${ }^{\star} p<0.01$; $t p=0.1$.

25.9 (28.3 for boys and 23.4 for girls) for each 100000 children aged $0-15$ years, with two major peaks in 1983 and 1993 (fig 3). The analysis of those diagnosed during incidence peaks (1982-3 and 1992-3; 334 children) showed a significant difference in birth pattern over the year compared with the background population $\left(\mathrm{df}=11, \chi^{2}=22.4, \mathrm{p}<0.03\right)$, with more children than expected born in July and August $(\mathrm{p}<0.05, \mathrm{O} / \mathrm{E}=1.39$ and $\mathrm{p}<0.01$, $\mathrm{O} / \mathrm{E}=1.52$, respectively), and somewhat fewer than expected born in October $(p=0.1$, $\mathrm{O} / \mathrm{E}=0.69)$. Children diagnosed during periods of lower incidence (1977-80, 1984-5, and 1989-90; 492 children) showed no significant difference in birth seasonality.

Four hundred and thirty one of the children had an infection documented within the three months before diagnosis, mostly a common cold $(61 \%)$ or gastrointestinal illness $(10 \%)$, and these children showed a more marked birth seasonality compared with the background population $\left(\mathrm{df}=11, \chi^{2}=21.03\right.$, $\mathrm{p}<0.03$ ) (fig 4; table 1) than children who had no documented infection before diagnosis $\left(\chi^{2}=12.13\right)$. We found no significant association between month of birth and blood glucose values at diagnosis or duration of symptoms before diagnosis ( $\chi^{2}$ and ANOVA).

\section{Discussion}

In the Swedish health care system all children $0-15$ years of age are diagnosed and treated in paediatric departments. Thus, because there are no patients going to private doctors or district doctors we can be sure that we included all children with newly diagnosed diabetes in the study area.
In contrast to another Swedish study by Dahlquist and Källen, ${ }^{20}$ we found a significant difference in birth pattern in children who later developed diabetes compared with the general population. One explanation for the finding that the youngest age group had rather high $\mathrm{O} / \mathrm{E}$ ratios but not a significant birth seasonality over the year could be the fact that this group had the smallest number of children. Jongbloet et al found that more children with diabetes than expected were born in January and February. ${ }^{17}$ However, we found that more children with diabetes than expected were born during the summer, in agreement with Rothwell et al, ${ }^{18}$ especially those children who developed diabetes during years of high incidence and subgroups with high incidence. Although October was the predominant month of birth in the study by Helgasson and Jonasson, ${ }^{15}$ we found significantly fewer children than expected born in October, a finding seen in almost all subgroups. Several other studies have also reported that fewer diabetic patients than expected were born during the autumn months. ${ }^{17} 1920$ Thus, our results agree to some extent with some studies, ${ }^{15} 1718$ but conflict with another. ${ }^{19}$ One possible explanation could be methodological differences. In contrast to most other studies, we dealt with a completely ascertained population covering a limited geographical area. Another explanation could be that environmental factors have their peak at different periods of the year in different areas of the world, or that different environmental factors are of main importance. Are there environmental factors that affect the fetus or the newborn child during certain seasons that, to some extent, protect them against diabetes? Or are the initiating factors more common during certain seasons, explaining the low incidence among children born in the autumn, but high in those born in late summer? Viral infections during pregnancy, or early in life, may contribute to later development of insulin dependent diabetes, ${ }^{22-24}$ and such infections may affect pregnant women more often during certain times of the year, thereby contributing to the difference in seasonal variation of birth of children who develop diabetes. Coxsackie viruses are trophic to $\beta$ cells. ${ }^{25}{ }^{26}$ Lymphocytes from children with diabetes, stimulated with a peptide from GAD (glutamic acid decarboxylase) known to have a similar amino acid sequence to coxsackie $\mathrm{B}$ viruses, show increased interferon $\gamma$ (INF- $\gamma$ ) mRNA expression compared with unstimulated lymphocytes from the same patients. ${ }^{27} \mathrm{INF}-\gamma$ is produced mainly by the T helper type 1 (Th1) subset of T cells. ${ }^{1923}$ Thus, the autoimmune response in insulin dependent diabetes might involve disturbances in immunoregulatory circuits that lead to a dominance of Th1 over Th2 T cell subset function..$^{28}$ This process is most likely to occur in genetically predisposed individuals, in whom such an infection in the fetus or very early in life might affect the vulnerable immature immune system and cause the relevant disturbances in the immunoregulatory circuits. $^{22} 2629$ 
In addition, further coxsackie infection(s) later during infancy or childhood may serve as a promoting factor, a sequence known from animal studies. ${ }^{30}$ The percentage of coxsackie B positive children at onset of diagnosis is greater when the incidence of diabetes is high than when the incidence is low. ${ }^{31}$

We found incidence peaks in 1983 and 1993. We do not know of any epidemic infectious disease in the study area during these years, but there were similar incidence peaks of diabetes during 1983 in areas geographically close to Sweden. ${ }^{32} 33$

In summary, we have shown that there is a seasonal variation of birth in children who later develop diabetes, which suggests that environmental factors very early in life, during pregnancy, or in the neonatal period play a role in its development. Such factors seem to vary with season. In south east Sweden, children born in July and August seem to be more prone and children born in the autumn less prone to exposure to such factors. We are trying to identify these environmental factors by studying 24000 children in south east Sweden, who are being followed prospectively from pregnancy to the age of 5 years with regard to infections, early nutrition, and other environmental factors.

This study was supported by the Swedish Child Diabetes Foundation (Barndiabetesfonden) and the County Council of Blekinge. We are grateful to the nurses and doctors in charge of diabetes care at the paediatric departments in Jönköping,
Kalmar, Karlskrona, Linköping, Norrköping, Västervik, and Växjö for providing patient data. Special thanks to Professor J Carstensen for statistical advice and Dr H Edenwall for advice regarding the manuscript.

1 Eisenbarth GS. Type 1 diabetes a chronic autoimmune disease. N Engl F Med 1986;22:1360-8.

2 Riley WJ, Maclaren NK, Silverstein, JH. The predictability of insulin-dependent diabetes mellitus. Adv Pediatr 1988; 35:167-88

3 Bateman A, Singh A, Kral T, Solomon S. The immune hypothalamic-pituitary-adrenal axis. Endocr Rev 1989;10: hypothalam 112 .

4 Bartrop RW, Lazarus L, Lockhurst E, Kiloh LG, Penny R. Depressed lymphocyte function after bereavement. Lancet 1977;i:834-6.

5 Dorian BJ, Keystone W, Garfinkel PE, Brown GM. Immune mechanisms in acute psychological stress. Psychosom Med 1981;43:84.

6 Afoke AO, Eeg-Olofsson O, Hed J, Kjellman N-IM, Lindblom B, Ludvigsson J. Seasonal variation and sex differences of circulating macrophages, immunoglobulins and lymphocytes in healthy school children. Scand $\mathcal{f}$ Immunol 1993;37:209-15.

7 Morrison-Smith J, Springer VH. Atopic disease and month of birth. Clin Allergy 1979;9:153-7.

8 Holt PG. Environmental factors and primary T-cell sensitisation to inhalant allergens in infancy: reappraisal of the sation to inhalant allergens in infancy: reappraisal of the
role of infections and air pollution. Pediatr Allergy Immunol 1995;6:1-10

9 Nilsson L, Björksten B, Hattevig G, Kjellman B, Sigurs N, Kjellman N-IM. Season of birth as predictor of atopic manifestations. Arch Dis Child 1997;76:341-4.

10 Åberg N. Birth season variation in asthma and allergic rhinitis. Clin Exp Allergy 1989;19:643-8.
11 Dahlquist G, Blom L, Hägglöf B, Larsson Y, Sterky G, Wall $\mathrm{S}$. The epidemiology of diabetes in Swedish children 0-14 years-a six year prospective study. Diabetologia 1985;28: $802-8$

12 Goday A, Castell C, Tresserras R, Canela J, Taberner JL, Lloveras G. Incidence of type 1 (insulin-dependent) diabetes mellitus in Catalonia, Spain. Diabetologia 1992;35: 267-71.

13 Afoke A, Ludvigsson J, Hed J, Lindblom B. Raised IgG and $\operatorname{IgM}$ in "epidemic" IDDM suggest that infections are IgM in "epidemic" IDDM suggest that infections are
responsible for the seasonality of type 1 diabetes. Diabetes Res 1991;16:11-17.

14 Ludvigsson J, Afoke AO. Seasonality of type 1 (insulindependent) diabetes mellitus: values of C-peptide, insulin antibodies and haemoglobin A1c levels show evidence of a more rapid loss of insulin secretion in epidemic cases. Diabetologia 1989;32:84-91.

15 Helgason T, Jonasson MR. Evidence for a food additive as a cause of ketosis-prone diabetes. Lancet 1981;ii:716-20.

16 Helgason T, Ewen SW, Ross IS, Stowers JM. Diabetes produced in mice by smoked/cured mutton. Lancet 1982;ii: $1017-22$

17 Jongbloet $\mathrm{PH}$, van Soestbergen M, van der Veen EA. Month of birth distribution of diabetics and ovopathy: a new aetioogical view. Diabetes Res 1988;9:51-8.

18 Rothwell PM, Staines A, Smail P, Wadsworth E, McKinney PA. Seasonality of birth of patients with childhood diabetes in Britain. BMF 1996;312:1456-7.

19 Block T, Pedersen CR, Volund A, Pallesen C, Buschard K. Perinatal determinants among children who later develop IDDM. Diabetes Care 1994;17:1154-7.

20 Dahlquist GG, Källen BAJ. Time-space clustering of date birth in childhood-onset diabetes. Diabetes Care 1996;19: 328-32.

21 Samuelsson U, Johansson C, Carstensen J, Ludvigsson. Space-time clustering in insulin-dependent diabetes mellitus (IDDM) in south-east Sweden. Int $\mathcal{F}$ Epidemiol 1994;23:138-42.

22 Dahlquist G, Ivarsson S, Lindberg B, Forsgren M. Maternal enteroviral infections during pregnancy as a risk factor for childhood IDDM. A population-based case-control study. Diabetes 1995;44:408-13.

23 Rubinstein P, Walker ME, Fedun B, Witt ME, Cooper LZ, Ginsberg-Fellner F. The HLA-system in congenital rubella in patients with and without diabetes. Diabetes 1982;31: 1088-91.

24 Ward KP, Galloway WH, Auchterlonie IA. Congenital cytomegalovirus and diabetes. Lancet 1979;i:497.

25 Schernthaner G, Banatvala JE, Scherbaum W, et al. Coxsackie-B-virus-specific IgM responses, complementfixing islet-cell antibodies, HLA DR antigens, and C-peptide secretion in insulin-dependent diabetes mellitus. Lancet 1985;ii:630-2.

26 Szopa TM, Titchener PA, Portwood ND, Taylor KW. Diabetes mellitus due to viruses-some recent developments. Diabetologia 1993;36:687-95.

27 Karlsson M, Ludvigsson J. GAD-peptide increases mRNA expression for cytokines in mononuclear cells of children with IDDM. Diabetologia 1996;39(suppl 7):A28.

28 Rabinovitch A. Immunoregulatory and cytokine imbalances in the pathogenesis of IDDM. Therapeutic intervention by immunostimulation. Diabetes 1994;43:613-21.

29 Dahlquist G, Frisk G, Ivarsson SA, Svanberg L, Forsgren $M$, Diderholm $H$. Indications that maternal coxsackie $B$ virus infection during pregnancy is a risk factor for childhood-onset IDDM. Diabetologia 1995;38:1371-3.

30 Oldstone MBA, Nerenberg M, Southern P, Price J, Lewicki $\mathrm{H}$. Virus infection triggers insulin-dependent diabetes mellitus in a transgenic model: role of anti-self (virus) immune response. Cell 1991;65:319-31.

31 Fohlman J, Friman G. Is juvenile diabetes a viral disease. Ann Med 1993;25:569-74.

32 Rewers M, LaPorte RE, Walczak M, Dmochowski K, Bogaczynska E. Apparent epidemic of insulin-dependent diabetes mellitus in midwestern Poland. Diabetes 1987;36: 106-13.

33 Hyöty H, Hiltunen M, Reunanen A, et al. Decline of mumps antibodies in type 1 (insulin-dependent) diabetic children an a plateau in the rising incidence of type 1 diabetes after introduction of the mumps-measles-rubella vaccine in Finland. Diabetologia 1993;36:1303-8. 